\title{
Prevalence of bronchiectasis among children less than twelve years of age in kurnool district
}

\section{Vedartham Ramesh.}

Assistant Professor in Peadiatrics, Viswabharathi Medical College, R. T. Nagar, Penchikalapadu, Kurnool, Andhra Pradesh, India.

\section{ABSTRACT}

\begin{abstract}
Background: In the modern era, the global burden of childhood Bronchiectasis remains poorly captured by the literature. However, bronchiectasis is essentially a disease of poverty. Clinical trials across multiple countries are essential to further improve interventional and clinical management of bronchiectasis. Hence, the present study taken up and studied the prevalence of bronchiectasis among children less than twelve years of age in kurnool district, India.

Materials and Methods: A descriptive study was design with 96 patients with bronchiectasis from Viswabharathi hospital medical college and all the children were followed up clinically and radiological findings. The details of these children were collected through a structured proforma and statistical analysis was done.

Results: Age groups below twelve years of age with the median age at presentation was 4.5 yrs and Male children (51.1\%) being slightly, occurs predominantly in lower socio-economic population (93\%) and urban population (55\%) being more affected. The common symptoms in these children are cough (100\%), fever (65\%) and breathlessness (53\%). Cough with expectoration (56.3\%) and hemoptysis (30.2\%) was predominant in above six years of age.

Conclusion: we present epidemiological data for bronchiectasis in Kurnool, A.P., India that will be important to inform quality improvement efforts in India as well as future clinical trial design and disease understanding. KEY WORDS: Breathlessness, Bronchiectasis, Cough, expectoration, fever, Hemoptysis.
\end{abstract}

Address for correspondence: Dr. Vedartham Ramesh, Assistant Professor in Peadiatrics, Viswabharathi Medical College, R. T. Nagar, Penchikalapadu, Kurnool, A.P., India-518467.

E-Mail: vedartham_r2006@yahoo.co.in

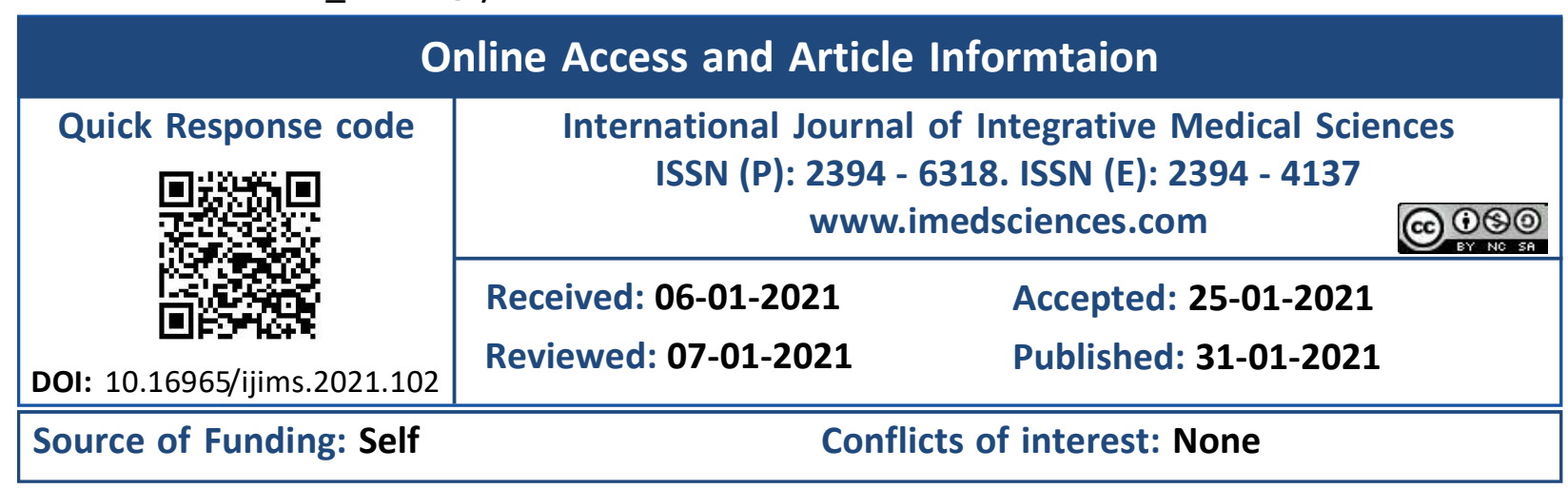

\section{INTRODUCTION}

In respiratory health, Bronchiectasis is one of the most chronic progressive disease of the airways with characterized by chronic productive or wet cough and abnormal dilatation of the bronchi caused by protracted inflammation [1]. Chest high resolution computer tomography (CHRCT) is the proper diagnosis test for bronchiectasis [1], with cases otherwise referred to as having chronic suppurative lung disease (CSLD) [1]. Congenital malformation, cystic fibrosis, or immune deficiency are multiple etiologies and are often associated with underlying conditions for Bronchiectasis or CSLD (from hereafter combined and referred to CSLD) [2]. However, in childhood acute lower respiratory infections (ALRI) is recurrent, a crucial time for lung growth and development, are arguably the common etiology for CSLD, particularly among socially disadvantaged children [1, 3].

Globally, over the last 50 years has declined the prevalence of CSLD with the use of antibiotics, immunizations, improved hygiene, nutrition, and access to medical care in developed countries [1]. However, among socially underprivileged populations of developed countries the substantial burden of CSLD in 
children, $[1,4]$ and with the extent of pediatric CSLD in developing countries largely unknown. In recent years, there has been a growing awareness of CSLD related to the increased use of CHRCT diagnostics and emerging research into the etiology, microbiology, immunology, and clinical management, yet, robust epidemiological data remain sparse $[1,5,6]$. Early diagnosis and intensive treatment protocols can stabilize or even improve the clinical prognosis of children with bronchiectasis [7]. Our understanding of the complex interplay between the host, pathogens, and the environment is largely superficial, and there have been few clinical intervention trials among children. There is a need for more epidemiological research globally to clarify the prevalence of CSLD, in particular, for at-risk populations in low- and middle- income countries. Importantly, there are also no longterm prospective studies in children to guide clinical care and management. Clinical trials across multiple countries are essential to further improve interventional and clinical management of CSLD. Hence, the present study taken up and studied the prevalence of bronchiectasis among children less than twelve years of age in kurnool district, India.

\section{MATERIALS AND METHODOLOGY}

A descriptive study was design with 96 children below 12 years of age, admitted in our institute with clinical and radiological diagnosis like chest X-ray / CT / HRCT of bronchiectasis in Viswabharathi medical college, Kurnool. All children included in this study were subjected to a detailed history regarding of symptoms. A thorough clinical observation was performed in all these patients with specific regards to anthropometry and signs suggesting chronicity of the disease process. Upper airways and lower respiratory system

\begin{tabular}{|c|c|c|c|c|c|}
\hline Symptoms & $\begin{array}{c}0-3 \text { yrs } \\
19(19.8 \%)\end{array}$ & $\begin{array}{c}4-6 \mathrm{yr} \\
25(26 \%)\end{array}$ & $\begin{array}{c}7-9 \text { yrs } \\
28(29.2 \%)\end{array}$ & $\begin{array}{l}10-12 \text { yrs } \\
24(25 \%)\end{array}$ & $\begin{array}{c}\text { Total } \\
96(100 \%)\end{array}$ \\
\hline Cough & $19(100 \%)$ & $25(100 \%)$ & $28(100 \%)$ & $24(100 \%)$ & $96(100 \%)$ \\
\hline Cough \& expectoration & - & $14(56 \%)$ & $21(75 \%)$ & 19 (79.2\%) & $54(56.3 \%)$ \\
\hline Breathlessness & $8(42.1 \%)$ & $11(40.0 \%)$ & $16(57.1 \%)$ & $15(62.5 \%)$ & $50(52.1 \%)$ \\
\hline Chest pain & - & $2(8.0 \%)$ & $4(14.2 \%)$ & $6(25.0 \%)$ & $12(12.5 \%)$ \\
\hline Wheeze & - & $3(12.0 \%)$ & $10(35.7 \%)$ & $7(29.1 \%)$ & $20(20.8 \%)$ \\
\hline Loss of wt & - & $4(16 \%)$ & $14(50.0 \%)$ & $17(70.8 \%)$ & $35(36.4 \%)$ \\
\hline Hemoptysis & - & $3(12.0 \%)$ & $13(46.4 \%)$ & $13(54.1 \%)$ & $29(30.2 \%)$ \\
\hline Persistent vomiting & $4(21.05 \%)$ & $3(12.0 \%)$ & - & $1(4.1 \%)$ & $8(8.3 \%)$ \\
\hline Clubbing & - & $7(28 \%)$ & $16(57.1 \%)$ & $14(58.3 \%)$ & $37(38.5 \%)$ \\
\hline Pallor & $4(21.05 \%)$ & $12(48 \%)$ & $14(50.0 \%)$ & $8(33.3 \%)$ & $38(39.6 \%)$ \\
\hline Lymphadenopathy & $3(15.7 \%)$ & $8(32 \%)$ & $6(21.4 \%)$ & $8(33.3 \%)$ & $25(26.0 \%)$ \\
\hline
\end{tabular}

were thoroughly examined, as were the other systems. All of these children were subjected to the following investigations like Chest X-Ray / X-Ray sinuses and radiological, High resolution computed tomography, Bacterial culture including Mycobacteria. All the children were followed up clinically and radiological findings. The details of these children were collected through a structured proforma and statistical analysis was done.

\section{RESULTS}

A total of 96 cases were recruited in the study. Males outnumbered females. Forty-nine (51.1\%) of the total number of children were males and forty-seven (48.9\%) were females.

Table 1: Showing the age and sex distribution of the study population.

\begin{tabular}{cccc}
\hline Age (years) & Male & Female & Total \\
\hline $\mathbf{0 - 3}$ yrs & $11(57.9 \%)$ & $8(42.1 \%)$ & $19(19.8 \%)$ \\
$\mathbf{4 - 6}$ yrs & $11(44 \%)$ & $14(56 \%)$ & $25(26 \%)$ \\
\hline $\mathbf{7 - 9}$ yrs & $14(50 \%)$ & $14(50 \%)$ & $28(29.2 \%)$ \\
\hline $\mathbf{1 0 - 1 2}$ yrs & $13(54.2 \%)$ & $11(45.8 \%)$ & $24(25 \%)$ \\
\hline Total & $49(51.1 \%)$ & $47(48.9 \%)$ & $96(100 \%)$ \\
\hline
\end{tabular}

In the study population $45.8 \%$ of all the patients were below 6 yrs of age and $54.2 \%$ of all the children were between the age group of 6 and 12 yrs. Females outnumbered males in the age group of 4 to 6 yrs. In our study population urban children outnumbered rural children constituting about $54.1 \%$ of all the children and $45.9 \%$ were from rural population. The duration between onset of symptoms and presentation was noted. Overall, the duration was between one to two years in $50 \%$ of the children. Among the age group of 0 to 3 years it was less than one year in $47.3 \%$ and between one to two years in $52.6 \%$. The duration for more than 3 yrs was commonly observed in the age group of 10 to $12 \mathrm{yrs}$, which was $54.2 \%$. The median age at presentation was 4.5 years.

Table 2: Showing the symptoms and signs in cases of bronchiectasis. 
Table 3: Showing the site of bronchiectasis in the study population.

\begin{tabular}{|c|c|c|c|c|c|c|c|c|c|}
\hline & \multirow{2}{*}{\multicolumn{4}{|c|}{$\begin{array}{c}\text { Right } \\
42(43.8 \%)\end{array}$}} & \multicolumn{4}{|c|}{ Left } & \multirow{3}{*}{$\begin{array}{c}\text { Bilateral / Both } \\
\text { Lower Lobe } 24 \\
(24.9 \%)\end{array}$} \\
\hline & & & & & \multicolumn{4}{|c|}{30 (31.3\%) } & \\
\hline & $\begin{array}{l}\text { Upper } \\
\text { Lobe }\end{array}$ & $\begin{array}{l}\text { Middle } \\
\text { Lobe }\end{array}$ & $\begin{array}{l}\text { Lower } \\
\text { Lobe }\end{array}$ & $\begin{array}{l}\text { Middle Lobe and } \\
\text { Lower Lobe }\end{array}$ & $\begin{array}{l}\text { Upper } \\
\text { Lobe }\end{array}$ & $\begin{array}{l}\text { Middle } \\
\text { Lobe }\end{array}$ & $\begin{array}{l}\text { Lower } \\
\text { Lobe }\end{array}$ & $\begin{array}{l}\text { Middle Lobe and } \\
\text { Lower Lobe }\end{array}$ & \\
\hline $0-3$ yrs & - & - & $12(46.1 \%)$ & $3(27.2 \%)$ & - & - & 4 (21.1\%) & - & 3 (12.5\%) \\
\hline 4-6 yrs & $1(20 \%)$ & - & $8(30.7 \%)$ & $3(27.2 \%)$ & $1(100 \%)$ & - & $5(26.3 \%)$ & $2(20 \%)$ & $10(41.6 \%)$ \\
\hline 7-9 yrs & $2(40 \%)$ & - & $13(50 \%)$ & $5(45.4 \%)$ & - & - & $7(36.8 \%)$ & $3(30 \%)$ & $5(20.8 \%)$ \\
\hline $10-12$ yrs & $2(40 \%)$ & - & $4(15.3 \%)$ & - & - & - & $13(68.4 \%)$ & $5(50 \%)$ & $6(25 \%)$ \\
\hline TOTAL & 5 (11.9\%) & - & 26 (61.9\%) & $11(26.2 \%)$ & $1(3.3 \%)$ & - & $19(63.3 \%)$ & $10(33.3 \%)$ & 24 \\
\hline
\end{tabular}

Table 4: Showing the Radiological Findings in Bronchiectasis in study population.

\begin{tabular}{|c|c|c|c|c|c|c|c|c|c|}
\hline & \multicolumn{4}{|c|}{ Right 42 (43.8\%) } & \multicolumn{4}{|c|}{ Left30 (31.3\%) } & \multirow[b]{2}{*}{$\begin{array}{c}\text { Bilateral / Both } \\
\text { Lower Lobe } 24 \\
(24.9 \%)\end{array}$} \\
\hline & $\begin{array}{l}\text { Upper } \\
\text { Lobe }\end{array}$ & $\begin{array}{l}\text { Middle } \\
\text { Lobe }\end{array}$ & $\begin{array}{l}\text { Lower } \\
\text { Lobe }\end{array}$ & $\begin{array}{l}\text { Middle Lobe } \\
\text { and Lower } \\
\text { Lobe }\end{array}$ & $\begin{array}{l}\text { Upper } \\
\text { Lobe }\end{array}$ & $\begin{array}{l}\text { Middle } \\
\text { Lobe }\end{array}$ & $\begin{array}{l}\text { Lower } \\
\text { Lobe }\end{array}$ & $\begin{array}{l}\text { Middle Lobe } \\
\text { and Lower } \\
\text { Lobe }\end{array}$ & \\
\hline $\begin{array}{c}\text { Cylindrical type } 56 \\
(58.3 \%)\end{array}$ & 2 & - & 14 & 7 & - & - & 12 & 5 & 16 \\
\hline $\begin{array}{c}\text { Cystic/saccular Type } 35 \\
(36.4 \%)\end{array}$ & 2 & - & 10 & 4 & 1 & - & 6 & 4 & 8 \\
\hline Varicose type 5 (5.2 \%) & 1 & - & 2 & - & - & - & 1 & 1 & - \\
\hline
\end{tabular}

\section{Cough was the universal complaint, but cough} with expectoration was mainly seen in the age group of 7 to 12 yrs (75\% -79.2\%). Breathlessness was one of the major complaints (52.1\%). Hemoptysis was seen mainly in the age group of 7 to 12 yrs (46.4\% $-54.1 \%)$. Loss of weight was mainly seen in the group of 10 to $12 \mathrm{yrs}$ (70.8\%). Chest pain and wheeze were in lesser proportion of the patients. Clubbing was noticed in $38.5 \%$ of the total study population, which was mainly seen in the age group of 10 to 12 yrs (58.3\%). Pallor was noticed in $39.6 \%$ and lymphadenopathy was seen in 26.0\% (Table 2).

Analysis of chest $x$-ray of all the patients revealed that left lung was mainly involved in the age group of 10 to 12 yrs, where tuberculosis etiology was commonly present. Right lung was mainly involved in the age group of 0 to 6 yrs, where aspiration, foreign body and congenital airway anomaly were the major etiological factors. Middle lobe on right side or lingula on left side were not involved as an isolated lesion. But over all right lung was commonly involved, affecting $42(43.8 \%)$ cases and left lung was involved in $30(30.3 \%)$ cases. $24(24.9 \%)$ the cases had bilateral involvement (Table 3)

Among the total of 96 cases 51 children were subjected for sputum culture analysis of which $6(11.7 \%)$ cases had Klebsiella growth in their sputum. Mycobacterium growth was seen in 2
(3.9\%) cases and streptococci growth was seen in $2(3.9 \%)$ cases. While one $(1.9 \%)$ had pseudomonas growth.34 (66.7\%) had no pathogenic growth in their sputum (Table 5).

Table 5: Showing the SPUTUM CULTURE IN BRONCHIECTASIS $(n=51)$.

\begin{tabular}{lccccc}
\hline \multicolumn{1}{c}{ Growth } & $\mathbf{0 - 3}$ yrs & $\mathbf{4 - 6}$ yr & $\mathbf{7 - 9}$ yrs & $\mathbf{1 0 - 1 2}$ yrs & Total \\
\hline Klebsiella & - & 1 & 3 & 3 & $6(11.7 \%)$ \\
Streptococci & - & - & 1 & - & $2(3.9 \%)$ \\
Mycobacterium & - & - & - & 2 & $2(3.9 \%)$ \\
Pseudomonas & - & 1 & - & - & $1(1.9 \%)$ \\
No growth & - & 3 & 14 & 17 & $34(66.7 \%)$ \\
\hline
\end{tabular}

Table 6: Showing the social economic status - modified kuppuswamy scale.

\begin{tabular}{cccc}
\hline & Rural & Urban & Total \\
\hline Class-I & - & - & - \\
\hline Class-II & $2(33.3 \%)$ & $4(66.7 \%)$ & $6(6.3 \%)$ \\
\hline Class-III & $14(37.8 \%)$ & $23(62.2 \%)$ & $37(38.5 \%)$ \\
\hline Class-IV & $28(52.8 \%)$ & $25(47.2 \%)$ & $53(55.2 \%)$ \\
\hline
\end{tabular}

Table no 6 showing the majority of the children were belonged to class IV socio economic class (according to modified Kuppuswamy scale) constituting about $55.2 \%$ of the total study population and $38.5 \%$ of the total belonged to class III socio economic class. None of the children belonged to class I socioeconomic class.

\section{DISCUSSION}

Bronchiectasis is a chronic lung disease characterized by abnormal permanent dilatation of one or more segmental bronchi, which typically involves second to sixth order of segmental bronchi with accumulation of 
exudative material resulting in chronic cough and foul-smelling sputum. It is an important cause for chronic cough in children. The incidence is declining following availability of vaccines like Measles, Pertussis, Hemophilus influenza, Pneumococcal vaccines and effective control of respiratory infection. This is more so in the developed countries, but in developing countries like India, post infection bronchiectasis still remains as an important problem. Like any other chronic disease, prevention is the only way to effectively reduce the incidence as there is no effective therapy, once the disease is established and permanent damage occurred. Henceforth it is important to know the etiological and epidemiological factors of bronchiectasis which will be helpful in preventing this permanent damage. In our study population, 96 cases of bronchiectasis were included of which, $45.8 \%$ of all the patients were below 6 yrs of age and $54.2 \%$ of all the children were between the age group of 6 and 12 yrs.

Males outnumbered females. Forty-nine (51.1 $\%)$ of the total number of children were males and forty-seven (48.9\%) were females. In their study, Hanaa Hasan Banjar, et al (8) Studied 151 cases of bronchiectasis, report similar sex distribution $49.7 \%$ were males and $50.3 \%$ were females. In another study by K. K. Khanna, et al (9) from the Department of Paediatrics, Jawaharlal Institute of Postgraduate Medical Education and Research, Pondicherry, studied 30 cases of bronchiectasis in childhood. $46.7 \%$ of the cases were in the age range of five to eight years and $36.6 \%$ in the age range of nine to twelve years. In our study, Urban population (54.1\%) outnumbered the rural population (45.9\%). This observation could be due to the reason that ours being tertiary centre and majority of the cases are referred cases. Since most of the studies were from western countries, they have not stressed upon the socioeconomic status, but in country like India it is one of the important factors which has got impact on overall morbidity and mortality and also overcrowding is one of the risk factors for communicable diseases. In present study, cough was the universal complaint, but cough with expectoration was mainly seen in the age group of 7 to 12 yrs (75\% -79.2\%). Breathlessness was one of the major complaints (52.1\%). Hemoptysis was seen mainly in the age group of 7 to $12 \mathrm{yrs}(46.4 \%-54.1 \%)$. Loss of weight was mainly seen in the group of 10 to 12 yrs (70.8\%). Clubbing was noticed in $38.5 \%$ of the total study population, which was mainly seen in the age group of 10 to 12 yrs (58.3\%). Pallor was noticed in $39.6 \%$ and Lymphadenopathy was seen in $26.0 \%$. In their study, Hanaa Hasan Banjar et al (8) where they have studied 151 cases of bronchiectasis had similar findings. More than two-thirds of the patients had cough, tachypnea, wheezing, sputum production and failure to thrive. In a study by $\mathrm{k} k$ khanna, et al [9] similar findings were present. Cough with expectoration was the commonest symptom which was seen in $64.4 \%$ of cases followed by haemoptysis present in $38 \%$ of cases.

In our study, analysis of chest x-ray of all the patients revealed that left lung was mainly involved in the age group of 10 to $12 \mathrm{yrs}$, where tuberculous etiology was commonly present. Right lung was mainly involved in the age group of 0 to 6 yrs, where aspiration, foreign body and congenital airway anomaly were the major etiological factors. But over all right lung was commonly involved, affecting 42 (43.8\%) of cases and left lung was involved in 30 (30.3\%) of cases. 24 (24.9\%) of the cases had bilateral involvement in a study by KK Khanna [9], unilateral bronchiectasis was more common than bilateral. Lingular involvement alone was not demonstrated. The posterior basal segment of the left lower lobe was the segment affected in majority of the cases but in our study overall it was right side which was commonly affected. This is similar to our study where unilateral involvement was more common than bilateral involvement and either middle lobe on right side or lingula on left side was not involved as an isolated lesion.

In a study by $C$. Elaine Field, et al [10] studied 160 cases of irreversible bronchiectasis in childhood. In $85.6 \%$ of cases the disease was situated in the left lower lobe, and in $65.6 \%$, in the lingula lobe, but in no case was the lingula affected as the only lobe. Massive collapse of the lung was associated with 
bronchiectasis in 74 (46.3\%) cases. Bronchoscopy was not helpful in diagnosis or localization of bronchiectasis. These findings had radiological correlation as well; hence bronchoscopy was very useful in knowing the causes as well localizing the bronchiectasis in our study. In our study sputum culture was done for 51 cases of which $6(11.7 \%)$ cases had kliebsiella growth in their sputum. Mycobacterium growth was seen in $2(3.9 \%)$ of cases and streptococci growth was seen in 2 (3.9\%) of cases. While one $(1.9 \%)$ had pseudomonas growth. 34 (66.7\%) had no pathogenic growth in their sputum. In the study by Hanaa Hasan Banjar, et al [8] Hemophilus influenza was cultured in 56 (37\%), strept pneumoniae in 25 (17\%) and pseudomonas aeruginosa in 24 (16\%) of the patients. In our study Kliebsiella growth was more commonly seen than the other bacterial culture this disparity could be due to variability in the prevalence of the pathogenic organisms at different places.

In our study, Urban population (54.1\%) outnumbered the rural population (45.9\%). This observation could be due to the reason that ours being tertiary centre and majority of the cases are referred cases. Majority of the children belonged to class IV socio-economic class (according to modified Kuppuswamy scale) constituting about $55.2 \%$ of the total study population and $38.5 \%$ of the total belonged to class III socio-economic class. None of the children belonged to class I socioeconomic class. Since most of the studies were from western countries they have not stressed upon the socio-economic status, but in country like India it is one of the important factor which has got impact on overall morbidity and mortality and also overcrowding is one of the risk factors for communicable diseases.

The World Health Organization recognizes asthma as a major health problem. Still, there is paucity of data on the prevalence of Bronchiectasis in children in India. Our summary from research studies of Childhood Bronchiectasis is that Bronchial Asthma affects a large number of children in India and the findings indicate that prevalence of Bronchial Asthma in children in India is increasing at a faster rate than previously understood. Due to lack of national representative data on the prevalence, risk factors, and prognosis of the disease, there is an urgent need for more public health research in this field of priority attention and direction.

\section{CONCLUSION}

In the present study, the Bronchiectasis occurs uniformly in all the age groups below twelve years of age and Male children being slightly more affected than females. The common symptoms in these children are cough, fever and breathlessness. Cough with expectoration and hemoptysis was predominant in above six years of age. Bronchiectasis occurs predominantly in lower socio-economic population than the upper socio-economic population and urban population being more affected than the rural population. we present unique epidemiological data for bronchiectasis in India that will be important to inform quality improvement efforts in India as well as future clinical trial design and disease understanding.

\section{REFERENCES}

[1]. Gabrielle B. McCallum, Michael J. Binks. The Epidemiology of Chronic Suppurative Lung Disease and Bronchiectasis in Children and Adolescents. Front Pediatr. 2017; 5: 27.

[2]. Goyal V, Grimwood K, Marchant J, Masters IB, Chang $A B$. Pediatric bronchiectasis: no longer an orphan disease. Pediatr Pulmonol. 2016;51:45069.

[3]. Singleton RJ, Valery PC, Morris P, Byrnes CA, Grimwood K, Redding G, et al. Indigenous children from three countries with non-cystic fibrosis chronic suppurative lung disease/ bronchiectasis. Pediatr Pulmonol. 2014;49:189200.

[4]. Das L, Kovesi TA. Bronchiectasis in children from Qikiqtani (Baffin) Region, Nunavut, Canada. Ann Am Thorac Soc. 2015;12:96-100.

[5]. Grimwood K. Airway microbiology and host defences in paediatric non-CF bronchiectasis. Paediatr Respir Rev. 2011;12:111-8.

[6]. Chang AB, Grimwood K, Maguire G, King PT, Morris PS, Torzillo PJ. Management of bronchiectasis and chronic suppurative lung disease in indigenous children and adults from rural and remote Australian communities. Med J Aust. 2008;189:386-93.

[7]. Susan J. Pizzutto, Kim M. Hare, John W. Upham. Bronchiectasis in Children: Current Concepts in Immunology and Microbiology. Front Pediatr. 2017; 5: 123. 
Vedartham Ramesh.Prevalence of bronchiectasis among children less than twelve years of age in kurnool district.

[8]. Hanaa Hasan Banjar, Wihelmina Ventura. Bronchiectasis in children. Bahrain Medical Bulletin. 2006;28(2).

[9]. K.K. Khanna, M.Sivakami, Bronchiectasis in children, Indian journal of pediatrics. 1976;43.
[10]. Twiss J, Metcalfe R, Edwards E, Byrnes C, Bronchiectasis in children, Arch Dis Child. 2005; 90(7):737-40.

How to cite this article: Vedartham Ramesh. Prevalence of bronchiectasis among children less than twelve years of age in kurnool district. Int J Intg Med Sci 2021;8(1):959-964. DOI: 10.16965/ ijims.2021.102 